\title{
PENGARUH SUDUT KOLIMASI KOLIMATOR 2 TERHADAP RESOLUSI DAN INTENSITAS BERKAS DIFRAKTOMETER NEUTRON DN3
}

\author{
A. Fajar dan H. Mugirahardjo \\ Pusat Teknologi Bahan Industri Nuklir - BATAN \\ Kawasan Puspiptek Serpong , Tangerang 15314
}

Diterima 18 Februari 2010; Diterima dalam bentuk perbaikan 29 Maret 2010; Disetujui 09 April 2010

\begin{abstract}
ABSTRAK
PENGARUH SUDUT KOLIMASI KOLIMATOR 2 TERHADAP RESOLUSI DAN INTENSITAS BERKAS DIFRAKTOMETER NEUTRON DN3. Telah dilakukan studi efek perubahan sudut kolimasi kolimator 2 terhadap performa difraktometer neutron serbuk DN3. Semakin besar sudut kolimasi kolimator 2 maka intensitas berkas terukur di detektor utama juga semakin tinggi. Sebaliknya resolusi peralatan menjadi semakin rendah pada sudut hamburan rendah dan tinggi. Telah didiskusikan beberapa alternatif untuk meningkatkan kinerja peralatan DN3 dengan mempertimbangkan kompromi antara resolusi dan intensitas seperti peningkatan kolimasi berkas dan pemanfaatan sistem monokromator fokusing.
\end{abstract}

Kata Kunci : difraktometer, intensitas, resolusi, $\mathrm{TiO}_{2}$

\begin{abstract}
THE EFFECT OF COLLIMATION ANGLE OF COLLIMATOR-2 ON THE RESOLUTION AND BEAM INTENSITY OF NEUTRON DIFFRACTOMETER DN3. The changing effect of collimation angle of collimator 2 on the performance of neutron powder diffractometer DN3 has been studied. The increasing of collimation of collimator 2 cause the increasing of observed neutron beam intensity in main detector. In contrast the resolution become lower particularly in the low and high scattering angle. It has been discussed some alternatives to improve the performance of DN3 equipments compromising between resolution and intensity such as the increasing beam collimation and the utilization of focusing monochromator.
\end{abstract}

Key words : diffractometer, intensity, resolution, $\mathrm{TiO}_{2}$

\section{PENDAHULUAN}

D ifraktometer Neutron Serbuk Resolusi Tinggi (DN3) merupakan difraktometer yang digunakan untuk mempelajari struktur kristal dan magnetik dengan cuplikan serbuk. Berbagai cuplikan telah diukur menggunakan peralatan ini ${ }^{(1-9)}$. Pemanfaatan difraktometer neutron serbuk semakin meningkat setelah ditemukannya teknik analisis pola difraksi yakni metode Rietveld yang dapat digunakan untuk melakukan refinement profil puncak difraksi kompleks yang mengandung puncak yang saling tumpang tindih ${ }^{(10)}$. Teknik refinement profil ini bergantung pada pengetahuan yang presisi mengenai bentuk profil. Semakin tinggi resolusi peralatan yang digunakan maka akan meningkatkan kualitas informasi yang diperoleh dari profil dan memungkinkan untuk menentukan struktur yang lebih besar dan lebih kompleks. Namun peningkatan resolusi peralatan ini biasanya tidak diiringi dengan peningkatan intensitas.

Eksperimen difraksi neutron biasanya memerlukan waktu yang lebih panjang untuk memperoleh data yang berkualitas tinggi karena amplitudo hamburan neutron jauh lebih kecil dibandingkan dengan sinar $\mathrm{X}$. Peralatan DN3 ditempatkan pada tabung pemandu neutron 2 yang berjarak 71 meter dari teras reaktor. Keuntungannya cacahan latar neutron sangat rendah. Namun demikian, selain disebabkan jarak yang jauh juga dimensi luas penampang tabung pemandu yang kecil, intensitas neutron yang sampai pada peralatan ini sudah sangat jauh menurun dibandingkan di reaktor. Ditambah lagi DN3 didesain untuk peralatan dengan resolusi tinggi menyebabkan intensitas neutron pada posisi cuplikan semakin rendah. Dengan demikian waktu pengukuran pola difraksi menjadi sangat panjang. Sebagai perbandingan ${ }^{(11)}$, intensitas maksimum dari salah satu cuplikan apatites yang diperoleh dari DN3 adalah 7,6 counts/jam sedangkan dari difraktometer ECHIDNA yang berada di ANSTO adalah 773 counts/jam. Karena itulah peningkatan intensitas hamburan neutron 
diperlukan dalam pengukuran difraksi neutron. Tetapi di sisi lain intensitas hamburan puncak Bragg pada dasarnya berbanding terbalik dengan resolusi, sehingga diperlukan optimasi antara intensitas dan resolusi untuk mencapai kinerja yang baik.

Resolusi dan intensitas dari peralatan difraktometer neutron termal dengan panjang gelombang monokromatis tertentu tergantung pada divergensi horizontal dari berkas neutron dan mozaik monokromator. Untuk resolusi ditambah lagi dengan sudut hamburan pada posisi monokromator dan cuplikan ${ }^{(12,13)}$. Untuk peralatan DN3, kolimasi pertama $\alpha_{1}$ berupa tabung pemandu neutron dan mozaik monokromator, $\beta$, semua nilainya sudah tertentu, maka resolusi peralatan tergantung pada modifikasi sudut monokromator $2 \theta_{\mathrm{M}}$, kolimasi kolimator 2, $\alpha_{2}$, yang berada di antara monokromator dan cuplikan dan kolimasi kolimator $3, \alpha_{1}$, yang berada di depan detektor utama setelah cuplikan. Skema peralatan DN3 dapat dilihat pada Gambar 1 di bawah ini.

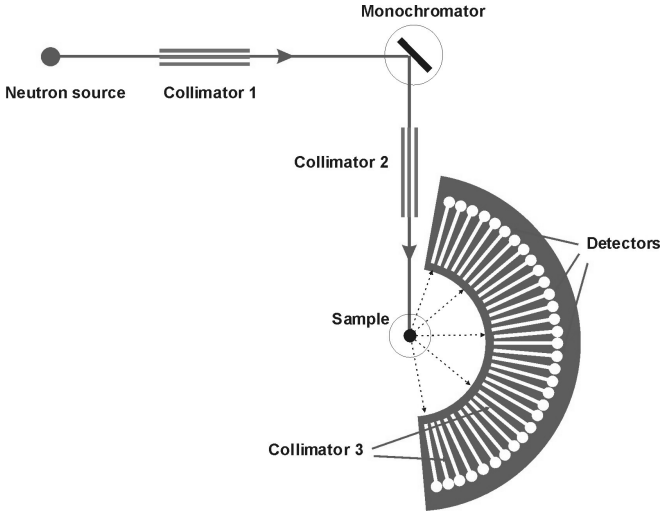

Gambar 1. Skema peralatan difraktometer neutron serbuk resolusi tinggi, DN3

Pada makalah terdahulu telah dipelajari efek divergensi horizontal kolimator 3 dan penurunan daya reaktor G.A. Siwabessy terhadap kinerja difraktometer neutron serbuk DN3 ${ }^{(14)}$. Sudut kolimasi yang lebih kecil menyebabkan resolusi peralatan menjadi lebih baik, namun intensitas hamburan menjadi lebih kecil. Dalam makalah ini akan dilakukan perbandingan kinerja peralatan DN3 dengan penggantian kolimator 2 yang terletak di antara monokromator dan cuplikan dengan melihat perubahan intensitas dan resolusi peralatan secara kuantitatif. Hal ini dilakukan sebagai bahan pertimbangan untuk meningkatkan kinerja peralatan DN3 pada waktu mendatang.

\section{METODOLOGI}

Cuplikan yang digunakan dalam eksperimen ini adalah $\mathrm{TiO}_{2}$ berbentuk bulk silinder yang diperoleh dari ANSTO dan diletakkan pada goniometer cuplikan. Pengukuran pola difraksi dilakukan menggunakan peralatan difraktometer neutron serbuk resolusi tinggi (DN3) yang terdapat di Pusat Teknologi Bahan Industri Nuklir -BATAN dengan panjang gelombang monokromator neutron termal $1,8223 \AA$ yang dihasilkan oleh monokromator hot-pressed $\mathrm{Ge}(331)^{(15-17)}$. Data difraksi dikumpulkan pada sudut $2 \theta$ antara $2,5^{\circ}$ hingga $157,5^{\circ}$ dengan langkah $0,05^{\circ}$ pada suhu ruang.

Pengamatan pengaruh perubahan kolimasi berkas neutron pada kolimator 2, pengukuran pola difraksi dilakukan dengan mengganti kolimator yang memiliki sudut divergensi horizontal yang berbeda yakni 20', 40' dan tanpa kolimator. Kolimator memiliki ukuran luar $65 \times 140 \times 390 \mathrm{~mm}^{3}$. Kolimator $20^{\prime}$ terdiri dari 11 lembar mylar yang dilapisi gadolinium oksida dan tersusun dengan jarak sama pada penampang seluas $25 \times 100 \mathrm{~mm}^{2}$, dan kolimator 40' terdiri dari 8 lembar mylar pada penampang seluas $35 \times 100 \mathrm{~mm}^{2}$. Pada setiap eksperimen digunakan beam narrower atau slit berkas di antara monokromator dan cuplikan setelah detektor monitor dengan ukuran tetap yakni $15 \times 45 \mathrm{~mm}^{2}$.

Data difraksi neutron yang diperoleh dianalisis dengan metode Rietveld menggunakan program RIETAN $2000^{(18)}$ untuk memperoleh data refinement parameter struktur cuplikan. Kurva resolusi peralatan digambarkan 
Pengaruh Sudut Kolimasi Kolimator 2 Terhadap Resolusi dan lintensitas Berkas Difraktometer Neutron DN3 (A. Fajar dan H. Mugirahardjo)

sebagai perubahan FWHM puncak difraksi Bragg terhadap sudut hamburan dari puncak Bragg yang diperoleh dari keluaran program. Kualitas refinement ditunjukkan oleh faktor reliabilitas sebagai berikut ${ }^{(19)}$ :

$$
\begin{array}{ll}
R_{w p}=\left\{\frac{\sum w_{i}\left(y_{i}(\text { obs })-\left.y_{i}(\text { calc })\right|^{2}\right.}{\sum w_{i}\left(y_{i}(o b s)\right)^{2}}\right\}^{1 / 2} & \text { (R-weighted pattern) } \\
R_{e}=\left\{\frac{N_{p}-N_{T}-N_{c}}{\sum w_{i}\left(y_{i}(o b s)\right)^{2}}\right\}^{1 / 2} & \text { (R-expected) } \\
R_{p}=\frac{\sum \mid y_{i}(o b s)-y_{i}(\text { calc }) \mid}{\sum y_{i}(o b s)} & \text { (R-pattern) } \\
s=\left\{\frac{\sum w_{i}\left(y_{i}(\text { obs })-y_{i}(\text { calc })\right)^{2}}{N-P}\right\}^{1 / 2}=\frac{R_{w p}}{R_{e}} & \text { (Goodness-of-fit) }
\end{array}
$$

dimana $y_{i}(o b s)$ adalah intensitas observasi, $y_{i}\left(\right.$ calc) intensitas kalkulasi, $w$ weights, $N_{p}$ jumlah data, $N_{T}$ jumlah parameter yang dapat di-refine, dan $N_{c}$ jumlah konstrain.

\section{HASIL DAN PEMBAHASAN}

Pada Gambar 2 diperlihatkan pola difraksi neutron cuplikan batangan $\mathrm{TiO}_{2}$ menggunakan kolimator 2 yang berbeda yakni dengan kolimasi 20' (a), 40' (b) dan tanpa kolimator (c). Waktu pengukuran untuk masingmasing pola difraksi sedikit berbeda. Pada ketiga gambar tersebut juga ditampilkan hasil refinement dengan menggunakan perangkat lunak RIETAN2000. Bagian yang hilang pada pola difraksi menunjukkan posisi noise instrumentasi yang masuk. Adapun penyebabnya belum diketahui dengan jelas.

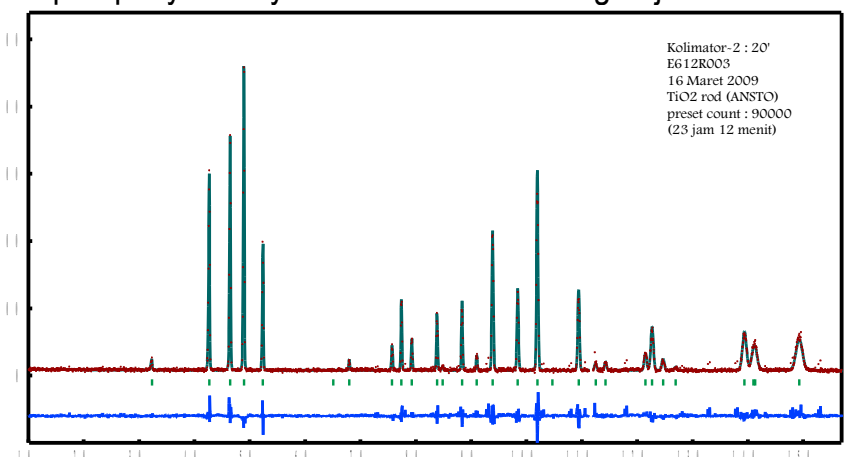

(a)

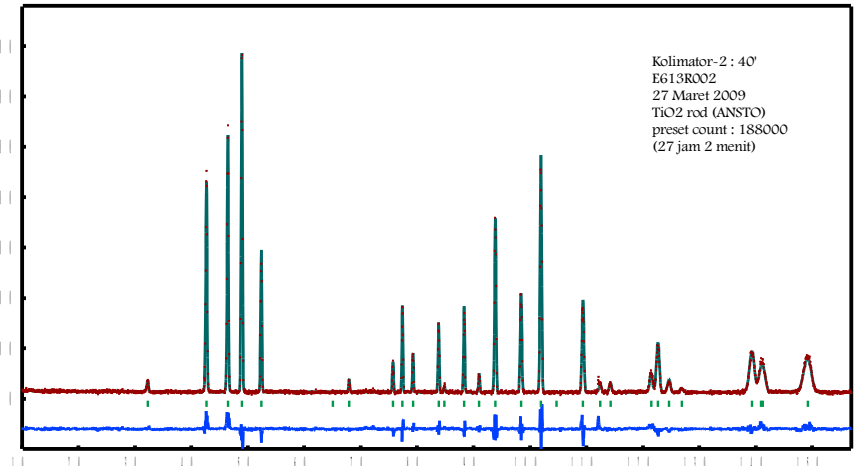

(b) 


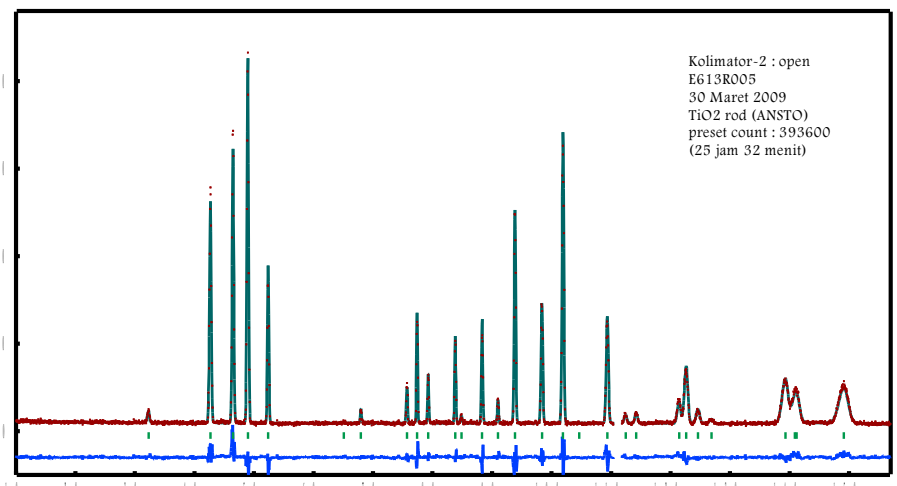

(c)

Gambar 2. Pola difraksi neutron dan hasil refinement Rietveld untuk cuplikan $\mathrm{TiO}_{2}$ pada suhu ruang menggunakan kolimator 2 dengan kolimasi (a) 20', (b) 40' dan tanpa kolimator (c). Titik-titik merupakan data pengukuran dan garis melalui titik-titik tersebut adalah hasil dari refinement. Posisi puncak Bragg dari $\mathrm{TiO}_{2}$ ditunjukkan sebagai garis vertikal pendek. Pada bagian bawah diperlihatkan perbedaan antara data pengukuran dan pola hasil perhitungan.

Tabel 1. Perbandingan kuantitatif untuk puncak difraksi Bragg bidang refleksi (111) untuk cuplikan $\mathrm{TiO}_{2}$, $2 \theta=48.944^{\circ}$ dengan luas beam narrower $1,5 \times 4,5 \mathrm{~cm}$

\begin{tabular}{|c|c|c|c|}
\hline Kolimator-2 & $20^{\prime}$ & $40^{\prime}$ & Open \\
\hline Waktu (jam) & 23,2 & 27,0 & 25,5 \\
Peak (counts) & 2302 & 3411 & 4327 \\
Peak/Waktu (c/h) & 99,2 & 126,3 & 169,7 \\
Background (counts) & 46 & 75 & 105 \\
BG/Waktu (c/h) & 2 & 2,8 & 4,1 \\
Rasio Peak to BG & 49,6 & 45,1 & 41,2 \\
\hline
\end{tabular}

Perbandingan yang menyolok dari ketiga pola difraksi dengan kolimasi yang berbeda-beda adalah pada intensitasnya. Pola difraksi yang diperoleh dari DN3 menggunakan kolimator dengan sudut divergensi yang lebih besar memiliki intensitas yang lebih tinggi selain dipengaruhi oleh lamanya waktu pengukuran cuplikan. Untuk membandingkan data ini secara kuantitatif perhatian akan difokuskan pada puncak difraksi (111) dari cuplikan $\mathrm{TiO}_{2}$ yang berada pada sudut hamburan sekitar $48,94^{\circ}$ seperti dirangkumkan dalam Tabel 1 . Dari nilai normalisasi intensitas puncak terhadap waktu terlihat bahwa dengan menggunakan kolimator 2 dengan kolimasi 40' intensitasnya meningkat $27,3 \%$ dibandingkan dengan kolimasi 20', dan tanpa kolimator mencapai $71,1 \%$. Namun sebaliknya, semakin besar sudut divergensi horizontal nilai rasio peak to background menjadi semakin rendah.

Kualitas data yang diperoleh diperlihatkan dari hasil refinement metode Rietveld seperti diperlihatkan pada Tabel 2 untuk cuplikan $\mathrm{TiO}_{2}$ batangan. Parameter kisi yang diperoleh sedikit berubah menjadi lebih besar dengan semakin besarnya sudut kolimasi horizontal yang sebenarnya tidak mungkin terjadi karena cuplikan yang digunakan sama untuk ketiga pola difraksi. Pada saat melakukan refinement Rietveld diasumsikan panjang gelombang yang menghasilkan ketiga pola difraksi di atas sama ini yakni 1,8223 A. Perubahan parameter yang semestinya tidak terjadi ini memperlihatkan bahwa terjadi perubahan panjang gelombang neutron monokromatis yang sampai di cuplikan karena perubahan alignment kolimasi berkas neutron yang melewati kolimator 2 . Sehingga parameter riil yang dapat ditentukan dari hasil ini hanya rasio c/a. Bila dihitung c/a dari hasil refinement pada Tabel 2 diperoleh nilai 0,644315 untuk kolimasi 20', 0,644312 untuk kolimasi 40' dan 0,644315 tanpa kolimator. Semua nilai hampir sama untuk semua refinement. Dari hasil ini dapat dilihat bahwa panjang 
parameter kisi dapat ditentukan dengan baik pada pola difraksi yang intensitasnya tinggi maupun pada data dengan intensitas rendah. Selain itu dapat dipahami bahwa perubahan sudut kolimasi horizontal berkas neutron pada kolimator 2 berpengaruh terhadap panjang gelombang sehingga perlu dilakukan kalibrasi panjang gelombang untuk memperoleh nilai yang benar. Dari harga $s$ yang menunjukkan kualitas refinement dapat diketahui bahwa hasil pengukuran pola difraksi menggunakan kolimasi yang berbeda memperlihatkan hasil refinement yang hampir sama. Adapun nilai Rwp yang diperoleh semakin kecil dengan semakin besarnya kolimasi. Hal ini dipahami dari persamaan (1), bahwa semakin tinggi nilai cacahan latar pola difraksi maka akan semakin kecil pula nilai Rwp yang diperoleh. Ini konsisten untuk semua hasil refinement. Begitu pula parameter posisi atom, $x$, dan parameter termal, Beq, pada masing-masing atom tidak terlihat perbedaan yang signifikan. Hal ini karena struktur cuplikan yang diukur relatif sederhana. Ada baiknya di waktu yang akan datang untuk membandingkan hasil refinement dari posisi atom untuk struktur yang lebih kompleks. Semakin tinggi resolusi dan tinggi intensitas data akan dapat mengamati posisi atom dengan lebih teliti.

Tabel 2. Parameter hasil refinement cuplikan $\mathrm{TiO}_{2}$ menggunakan RIETAN2000

\begin{tabular}{|c|c|c|c|}
\hline Kolimator-2 & $20^{\prime}$ & $40^{\prime}$ & Open \\
\hline Grup ruang & $\mathrm{P} 42 / \mathrm{mnm}$ & $\mathrm{P} 42 / \mathrm{mnm}$ & $\mathrm{P} 42 / \mathrm{mnm}$ \\
\hline$a(\AA)$ & $4,59497(7)$ & $4,59571(6)$ & $4,59724(6)$ \\
\hline$c(\AA)$ & $2,960606(6)$ & $2,96107(5)$ & $2,96207(4)$ \\
\hline$a=\beta=y$ & 90 & 90 & 90 \\
\hline$V(\AA ̊ 3)$ & $62,5095(18)$ & $62,5394(15)$ & $62,6023(15)$ \\
\hline $\operatorname{Rwp}(\%)$ & 15,46 & 11,78 & 10,53 \\
\hline $\mathrm{Rp}(\%)$ & 11,27 & 8,97 & 8,04 \\
\hline $\operatorname{Re}(\%)$ & 11,57 & 9,03 & 7,60 \\
\hline$s=\operatorname{Rwp} / \operatorname{Re}$ & 1,3363 & 1,3041 & 1,3860 \\
\hline $\mathrm{Ti}, 2 \mathrm{a}(\mathbf{0 , 0 , 0 )}$ & & & \\
\hline Occ. Fac. & 1 & 1 & 1 \\
\hline $\begin{array}{c}\text { Beq } \\
0,4 f(x, x, 0)\end{array}$ & $0,410(56)$ & $0,376(42)$ & $0,245(37)$ \\
\hline$x$ & $0,30541(18)$ & $0,30532(14)$ & $0,30570(12)$ \\
\hline Occ.Fac. & 1 & 1 & 1 \\
\hline Beq & $0,345(31)$ & $0,391(23)$ & $0,412(21)$ \\
\hline
\end{tabular}

Pada Gambar 3 diperlihatkan kurva resolusi peralatan (FWHM dan $\Delta d / d$ ) terhadap sudut hamburan yang diperoleh dari pola difraksi neutron menggunakan sudut divergensi horizontal kolimator 2 yang berbeda. Data ini diperoleh dari hasil keluaran program Rietan. Garis dalam gambar merupakan hasil fitting dengan menggunakan persamaan Caglioti ${ }^{(12)}$, sebagai berikut:

$$
\begin{aligned}
{[F W H M]^{2} } & =U \cdot \tan ^{2} \theta_{s}+V \cdot \tan \theta_{s}+W & & \text { untuk FWHM, } \\
\frac{\Delta d}{d} & =\cot \theta \Delta \theta & & \text { untuk } \Delta d / d
\end{aligned}
$$

Dari Gambar 3 terlihat bahwa resolusi peralatan DN3 (FWHM) berada di bawah 0,6 pada sudut hamburan yang lebih kecil dari $120^{\circ}$ yang merupakan lingkup sudut hamburan dengan jumlah puncak Bragg terbanyak untuk tiga kondisi eksperimen yang berbeda. Semakin besar sudut divergensi horizontal kolimator 2 maka resolusi peralatan semakin turun. Hal ini terutama terlihat pada sudut hamburan rendah di bawah $60^{\circ}$ dan pada sudut hamburan tinggi setelah sudut $120^{\circ}$. Tetapi resolusi tertinggi untuk semua pengukuran bisa dikatakan hampir sama yakni pada sudut hamburan sekitar $78^{\circ}$, di mana nilainya adalah $0,22^{\circ}$ untuk FWHM dan $4,7 \times 10^{-3}$ untuk $\Delta d / d$. Hasil ini sesuai dengan prediksi dari persamaan Caglioti ${ }^{(12)}$, bahwa semakin kecil sudut divergensi horizontal kolimator maka akan semakin tinggi resolusinya. Sebaliknya sebagaimana telah dibahas 
sebelumnya, semakin kecil kolimasi akan menyebabkan intensitas berkas neutron yang diterima detektor akan semakin rendah. Parameter hasil fitting kurva resolusi menggunakan persamaan (5) diperlihatkan pada Tabel 3.

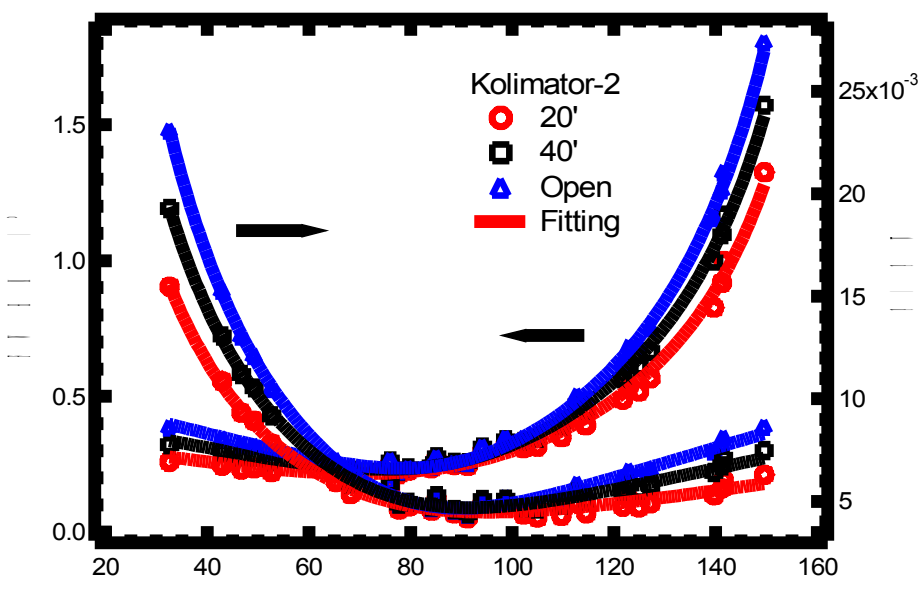

Gambar 3. Perubahan nilai FWHM dan $\Delta d / d$ terhadap sudut hamburan dari pola difraksi cuplikan $\mathrm{TiO}_{2}$.

Dari hasil-hasil di atas terlihat bahwa upaya meningkatkan resolusi peralatan menyebabkan intensitas berkas terukur menjadi turun. Kompromi antara resolusi yang berbanding terbalik dengan intensitas menjadi penting dalam meningkatkan kinerja peralatan DN3. Dalam kondisi seperti saat ini yang menggunakan kolimasi 20', pengukuran pola difraksi pada cuplikan dengan unsur-unsur yang memiliki panjang hamburan yang cukup besar tidak menjadi permasalahan. Tetapi untuk cuplikan yang terdiri dari atom-atom dengan panjang hamburan tidak begitu kuat akan dibutuhkan waktu pengukuran yang lama untuk memperoleh statistik data yang baik. Terutama pada cuplikan yang mengandung hidrogen. Pada umumnya rasio peak to background cuplikan ini sangat kecil karena hidrogen memberikan efek hamburan inkoheren yang menambah tinggi cacahan latar pada pola difraksi. Seperti terlihat pada Tabel 1 nilai peak to background pada saat menggunakan kolimator 2 dengan kolimasi $20^{\prime}$ lebih rendah dibandingkan dengan kolimasi $40^{\prime}$ dan open, sehingga diperlukan waktu yang lebih lama untuk mendapatkan data yang baik. Keterbatasan keberadaan neutron yang berasal dari reaktor menjadi pertimbangan untuk lebih meningkatkan efisiensi pemakaian berkas neutron.

Tabel 3. Parameter hasil fitting kurva resolusi menggunakan persamaan Caglioti

\begin{tabular}{|c|c|c|c|}
\hline Parameter & Kolimator 2: $20^{\prime}$ & Kolimator $2: 40^{\prime}$ & Kolimator 2: Open \\
\hline U & $0,179(7)$ & $0,271(7)$ & $0,377(7)$ \\
V & $-0,25(2)$ & $-0,41(2)$ & $-0.61(2)$ \\
W & $0,14(1)$ & $0,21(1)$ & $0,31(1)$ \\
\hline
\end{tabular}

Dari hasil ini ada beberapa hal yang dapat dilakukan untuk meningkatkan kinerja peralatan DN3. Misalnya adalah mempertimbangkan untuk menggunakan kolimator dengan kolimasi yang lebih besar atau dibuka sama sekali. Kemudian di depan kolimator 2 sebelum posisi cuplikan dipasangkan flight tube untuk meningkatkan kesejajaran berkas neutron yang datang dari monokromator sehingga diharapkan resolusi akan menjadi lebih baik dan intensitas dapat ditingkatkan karena tidak ada neutron yang terbuang serta menurunkan cacahan latar yang disebabkan oleh neutron terhambur. Selain itu perlu juga dipertimbangkan pemanfaatan sistem fokusing baik secara horizontal maupun vertikal pada monokromator sehingga berkas yang sampai pada cuplikan lebih tinggi intensitasnya.

\section{KESIMPULAN}

Telah dilakukan studi efek perubahan sudut divergensi horizontal kolimator 2 terhadap performa difraktometer neutron serbuk DN3. Semakin besar sudut divergensi horizontal kolimator 2 maka intensitas 
berkas terukur di detektor utama juga semakin tinggi. Sebaliknya, resolusi peralatan menjadi semakin rendah. Telah didiskusikan beberapa usulan kegiatan yang dapat dilakukan untuk meningkatkan intensitas hamburan peralatan DN3 tanpa kehilangan resolusi yang terlalu besar seperti penggunaan kolimasi berkas neutron yang lebih besar serta pengembangan sistem fokusing monokromator.

\section{UCAPAN TERIMA KASIH}

Penulis (A.F.) mengucapkan terima kasih Prof. Alan Hewat (NeutronOptics, mantan Kepala Grup Difraktometer, ILL) atas diskusinya mengenai peralatan DN3.

\section{DAFTAR PUSTAKA}

1. MUJAMILAH , RIDWAN, "Intensive Structural Investigation of $\mathrm{R}_{2} \mathrm{Fe}_{17-x} \mathrm{M}_{\mathrm{x}}$ Intermetallic Compounds Using High Resolution Powder Neutron Diffractometer", Proceedings of the 1997 Workshop on the Utilization of Research Reactor BATAN-JAERI, Bandung (1997) 210-239 (and references therein)

2. D.F. CHEN, C. GOU, K. SUN, Q.W. YAN, P.L. ZHANG, B.G. SHEN, H.Y. GONG, Z.H. CHENG, RIDWAN, MUJAMILAH, MARSONGKOHADI, High-concentration substitution of $\mathrm{Ga}$ and $\mathrm{Al}$ in $\mathrm{R}_{2} \mathrm{Fe}_{17}(\mathrm{R}=\mathrm{Ho}$ or $\mathrm{Y})$ : $A$ neutron study of crystallographic and magnetic structure, Physica B, 241-243 (1998) 640-642

3. W. PRASUAD, GUNAWAN, E. SUKIRMAN, PARIKIN, Y. HAMAGUCHI DAN I. SHIMONO, "Hubungan Suhu Transisi Kritis (Tc) Terhadap Perubahan Panjang Ikat Atom Cu-O (Apikal) Pada Superkonduktor Keramik $\mathrm{Bi}_{2} \mathrm{Sr}_{2} \mathrm{Ca}_{n} \mathrm{Cu}_{n+1} \mathrm{O}_{2 n+6}$ ( $\left.n=0,1,2\right)$ ", Prosiding Seminar Nasional Hasil Penelitian dan Pengembangan Fisika Terapan dan Lingkungan 1995/1996, Bandung (1996) 381-389 (and references therein)

4. E. SUKIRMAN, P. SULISWORO, W. PRASUAD AND WURYANTO, "Mechanism of Pb and Sb Role on the 2223 Phase of BSCCO System Superconductor", Proceedings of the 1997 Workshop on the Utilization of Research Reactor BATAN-JAERI, Bandung (1997) 197-209

5. ISMUNANDAR, B.J. KENNEDY, GUNAWAN, MARSONGKOHADI, Structure of $\mathrm{ABi}_{2} \mathrm{Nb}_{2} \mathrm{O}_{9}(\mathrm{~A}=\mathrm{Sr}, \mathrm{Ba})$ : Refinement of Powder Neutron Diffraction Data, J. Solid. Chem., 126 (1996) 135-141

6. E. M. WIGAYATI, E. Y. FEBRIANTO, A. FAJAR, Pembuatan Senyawa $\mathrm{Li}_{1,33} \mathrm{Mn}_{2} \mathrm{O}_{4}$ untuk Elektroda Baterai Padat Lithium, J. Sains Materi Ind., Edisi Khusus November, (2008) 201-204

7. A. FAJAR, H. MUGIRAHARDJO, GUNAWAN, SAIRUN, E. SANTOSO, Y. A. MULYANA, "Identifikasi Kandungan Fasa Kristalin Batuan Berharga Secara Tidak Merusak Menggunakan Difraksi Neutron", Prosiding Seminar Material Metalurgi, Serpong (2008) 317-322

8. STEVIN S. PRAMANA, T. J. WHITE, MARTIN K. SCHREYER, C. FERRARIS, P. R. SLATER, T. J. BASTOW, S. MANGOLD, S. DOYLE, L. TAO, A. FAJAR, M. SRINIVASAN, AND T. BAIKIE, "Pseudomorphic $2 \mathrm{~A} \rightarrow 2 \mathrm{M} \rightarrow 2 \mathrm{H}$ phase transitions in lanthanum strontium germanate electrolyte apatites", Dalton Transactions, 39 (2009) 8280-8291

9. PURWANTO, A. FAJAR, H. MUGIRAHARDJO, J.W. FERGUS AND K. WANG, Cation Distribution in Spinel $(\mathrm{Mn}, \mathrm{Co}, \mathrm{Cr})_{3} \mathrm{O}_{4}$ at Room Temperature, accepted to be published in J. Appl. Cryst., 43 (2010)

10. H. M. RIETVELD, A Profile Refinement Method for Nuclear and Magnetic Structure, J. Appl. Crystallogr., 2 (1969) 65-71

11. A. FAJAR AND H. MUGIRAHARDJO, "The Performance of Fine Resolution Neutron Powder Diffractometer at PTBIN-BATAN", accepted to be published in Atom Indonesia, 36 (2010)

12. G. CAGLIOTI, A. PAOLETTI, AND F.P RICCI, "Choice of collimators for a crystal spectrometer for neutron diffraction", Nucl. Instrum. Methods, 35 (1958) 223-228

13. W. HEWAT, "Design For A Conventional High-Resolution Neutron Powder Diffractometer", Nucl. Instrum. \& Methods, 127 (1975) 361-370

14. A. FAJAR AND H. MUGIRAHARDJO, "Efek Sudut Divergensi Horizontal Kolimator 3 Terhadap Performa Difraktometer Neutron Serbuk DN3", dipresentasikan pada seminar hamburan neutron dan sinar X ke-7, Serpong 27 Oktober 2009. 
15. IKRAM AND BHAROTO, Research and facility of neutron scattering in Indonesia, Physica B, 311 (2002) 1422

16. A. FAJAR, T.H. PRIYANTO, E. SANTOSO, H. MUGIRAHARDJO, N. SUPARNO, A. PURWANTO, "Neutron Diffraction Activities in Serpong", Neutron News, 18 (2007) 13-18

17. A. FAJAR, H. MUGIRAHARDJO, BHAROTO, E. SANTOSO, GUNAWAN, Pengembangan Difraktometer Neutron Serbuk Resolusi Tinggi Untuk Penelitian Struktur Bahan, J. Sains. Mat. Ind., Edisi Khusus Desember (2008) 271-281

18. F. IZUMI, Rietveld analysis and MEM-based whole pattern fitting under partial profile relaxation, Rigaku J., $17(2000) 34$

19. R.A. YOUNG, The Rietveld Method, International Union of Crystallography Oxford University, 1996. 